\title{
The Use of Telehealth Technology to Support Health Coaching for Older Adults: Literature Review
}

Carl Markert ${ }^{1}$, BS, MBA; Farzan Sasangohar ${ }^{1,2}$, BA, BCS, MASc, SM, PhD; Bobak J Mortazavi ${ }^{3}$, BA, BS, MS, PhD; Sherecce Fields ${ }^{4}$, BA, BS, MA, PhD

\footnotetext{
${ }^{1}$ Department of Industrial and Systems Engineering, Texas A\&M University, College Station, TX, United States

${ }^{2}$ Center for Outcome Research, Houston Methodist, Houston, TX, United States

${ }^{3}$ Department of Computer Science and Engineering, Texas A\&M University, College Station, TX, United States

${ }^{4}$ Department of Psychological and Brain Sciences, Texas A\&M University, College Station, TX, United States
}

\section{Corresponding Author:}

Farzan Sasangohar, BA, BCS, MASc, SM, PhD

Department of Industrial and Systems Engineering

Texas A\&M University

3131 TAMU

College Station, TX, 77843

United States

Phone: 19794582337

Email: sasangohar@tamu.edu

\section{Abstract}

Background: Health coaching is an intervention process for driving behavior change through goal-setting, education, encouragement, and feedback on health-related behaviors. Telehealth systems that include health coaching and remote monitoring are making inroads in managing chronic conditions and may be especially suited for older populations.

Objective: This literature review aimed to investigate the current status of health coaching interventions incorporating telehealth technology and the associated effectiveness of this intervention to deliver health care with an emphasis on older adults (aged 65 and older).

Methods: A literature review was conducted to identify the research conducted on health coaching combined with remote monitoring for delivering health care to older adults. The Ovid MEDLINE and CINAHL databases were queried using a combination of relevant search terms (including middle aged, aged, older adult, elderly, health coaching, and wellness coaching). The search retrieved 196 papers published from January 2010 to September 2019 in English. Following a systematic review process, the titles and abstracts of the papers retrieved were screened for applicability to health coaching for older adults to define a subset for further review. Papers were excluded if the studied population did not include older adults. The full text of the 42 papers in this subset was then reviewed, and 13 papers related to health coaching combined with remote monitoring for older adults were included in this review.

Results: Of the 13 studies reviewed, 10 found coaching supported by telehealth technology to provide effective outcomes. Effectiveness outcomes assessed in the studies included hospital admissions/re-admissions, mortality, hemoglobin $\mathrm{A}_{1 \mathrm{c}}\left(\mathrm{HbA}_{1 \mathrm{c}}\right)$ level, body weight, blood pressure, physical activity level, fatigue, quality of life, and user acceptance of the coaching program and technology.

Conclusions: Telehealth systems that include health coaching have been implemented in older populations as a viable intervention method for managing chronic conditions with mixed results. Health coaching combined with telehealth may be an effective solution for providing health care to older adults. However, health coaching is predominantly performed by human coaches with limited use of technology to augment or replace the human coach. The opportunity exists to expand health coaching to include automated coaching.

(JMIR Hum Factors 2021;8(1):e23796) doi: 10.2196/23796

\section{KEYWORDS}

telemedicine; remote sensing technology; health coaching; decision support systems; clinical; older adults 


\section{Introduction}

\section{Overview of Chronic Diseases}

Chronic diseases are health-related conditions that require ongoing medical attention or limit one's daily activities [1]. These conditions are common among older adults and were the leading causes of death among older adults (aged 65 and older) in the United States in 2017 [2]. Chronic disease management within the world's aging population is creating a burden on the health care industry [3]. For example, the average medical expenditures in the United States within this older population were 2.6 times the national average and accounted for over one-third of medical spending in 2010 [4]. A subsequent survey by the Kaiser Family Foundation found that older adults (age 55 and over) in the United States accounted for $56 \%$ of all health care spending in 2016 but made up only $29 \%$ of the population [5].

The Census Bureau projects that the US population aged 65 or older will grow from 49 million in 2016 to 95 million by 2060 [6]. Ninety percent of these older adults prefer to age in place, or remain in their homes as they grow older [7] which could also mitigate health care costs for this population compared to the cost of assisted living communities. Aging in place allows them to better maintain contact with friends and family, but this preference presents a challenge for determining what health-related technology is needed to help meet this desire [8]. Telehealth may be one way to effectively manage chronic diseases among older adults while also enabling them to live at home, especially with a number of opportunities available to assist aging in place through advancements in smart sensing technology [9]. Furthermore, the COVID-19 pandemic has also shown the necessity of understanding the efficacy of telehealth systems, as these systems may be the only mode of non-emergency health care delivery for vulnerable populations in a pandemic situation [10]. However, despite the increased access to telehealth technologies, implementation strategies that do not address self-management of one's health care have led to disappointing findings, such as the failure to reduce re-admissions in individuals with heart failure $[11,12]$.

While telehealth has enabled virtual visits with health care professionals, the self-management capabilities of telehealth require special attention to patient engagement and behavior change methods to improve active participation. Health coaching has gained widespread use in the past few years. Two recent systematic reviews found health coaching to be somewhat effective for adults with chronic conditions $[13,14]$. Kivelä et al [13] found health coaching to be effective for the patient's physiological, behavioral, and psychological status, specifically, improvements in weight management, physical activity, physical health, and mental health. Oliveira et al [14] found health coaching to be effective in increasing the level of physical activity in older adults but found no significant improvement in quality of life, mobility, or mood. Neither of these studies evaluated health coaching combined with remote monitoring. The goal of our review was to investigate the current status of health coaching interventions that incorporate telehealth remote

\section{Background}

Telehealth is an all-encompassing term for clinical and nonclinical remote health care services and is defined by the Center for Connected Health Policy as "a collection of means or methods for enhancing health care, public health and health education delivery and support using telecommunications technologies" [15]. For the purpose of this literature review, telehealth includes telemedicine, remote patient monitoring (RPM), remote activity monitoring (RAM), decision support systems (DSSs), and health coaching systems.

Telemedicine is the use of telecommunication technology to allow health care workers to provide clinical services (eg, medical therapy) to patients remotely [16]. Telemedicine is useful for providing clinical services to patients in sparsely populated areas or places remotely located from a health care facility [17].

$R P M$ is the use of electronic devices and telecommunication technology to monitor and transmit patient physiological or metabolic parameters to a digital database that can be accessed by authorized users [18]. RPM usually involves Bluetooth-enabled or internet-connected devices that automatically transmit monitored parameters. RPM can also include electronic wellness questionnaires that elicit information concerning the patient's well-being and health status.

$R A M$ is the use of electronic devices to provide remote monitoring of a person's mobility or activities of daily living (ADLs) [19]. ADLs can be remotely monitored using motion detection devices installed in a person's residence or a wearable device, such as a smart watch, that detects, records, and transmits movement activity. Another form of ADL monitoring is medication adherence monitored remotely via automated pillboxes. Automated pillboxes are used to organize medications, provide reminders to take medications, and provide information to clinicians via telehealth regarding medication use [20].

DSSs are electronic (computerized) systems which evaluate data collected via remote monitoring and transform the data into useful information regarding the patient's health and wellness [21]. The DSS makes clinical or behavioral recommendations based on an evaluation of the monitored data. An example of a recommendation is a reminder to the patient to take his/her medication if an automated pillbox senses the person has not taken their medication that day. If the medication is still not taken after some delay, the DSS can notify the health care providers or health coaching system. The DSS can also initiate an emergency notification to 911 if certain threshold values of monitored parameters are exceeded.

Health coaching systems are defined as "patient-centered processes that are based upon behavior change theory" and include goal setting, education, encouragement, and feedback on health-related behaviors [14]. Disease management, by contrast, focuses on the specific disease(s) instead of the patient's behavior [22]. Health coaching programs provide health-related information, recommendations, or encouragement to the patient on a routine or as-needed basis to help drive 
behavior changes [21]. Forms of health coaching include encouragement, feedback, health care suggestions, periodic health tips, or short educational presentations based on an analysis of the patient's health status and monitored data. An example of a coaching message is sleep management advice if the patient is not sleeping well. The health coaching system can be manual (human health coach only), partially automated, or fully automated using artificial intelligence and machine learning to generate health coaching messages to the patient.

\section{Methods}

A literature review was chosen for this study to identify the research conducted on the current state and effectiveness of health coaching combined with remote monitoring (RPM or RAM) and any knowledge gaps that warrant further research. This review was specifically focused on health coaching combined with telehealth to deliver health care with an emphasis on older adults. The Ovid MEDLINE and CINAHL databases were queried to first retrieve papers related to health or wellness coaching for populations that included older adults and to then narrow the results to those studies that included some form of remote monitoring. Given the rapid pace with which telehealth is advancing, results from 2010 or later were chosen for this search to focus on relatively current research. The full electronic search strategy was [(MH "Middle Aged") OR (MH "Aged+") OR AB (older adult* or elder* or aged) OR TI (older adult* or elder* or aged)] AND [AB ((health or wellness) n1 coaching)
OR TI ((health or wellness) n1 coaching)]. The search criteria included articles published from January 2010 to September 5, 2019 (date of search) in English. Keywords included those related to older populations (aged, elder, and older adult) and coaching (health or wellness coaching). This combination of search terms retrieved 225 papers relevant to health coaching. The review of these papers was conducted in accordance with the Preferred Reporting Items for Systematic Reviews and Meta-Analyses (PRISMA) guidelines (Figure 1) [23]. After deleting duplicates, 196 papers were included for an abstract review and screening. These abstracts were reviewed for studies that discussed health coaching for populations that included older adults (aged 65 and older) combined with some form of remote monitoring. The abstract screening yielded 42 articles for full-text review, of which 13 articles were identified that met the eligibility criteria (health coaching, remote monitoring, and older adults). Studies were excluded from our review if older populations (aged 65 and over) were not included, if the study did not include remote monitoring (RPM or RAM), or if the study did not include some form of coaching intervention. Subsequent to the review, 2 additional studies were identified [24,25] which provided the results for the ACTIVATE Trial [26] included in the original search. The results of the literature review were charted based on the following criteria: description of the coaching intervention, type of remote monitoring, study type, size of the study population, length of the study, condition monitored, and the outcomes. 
Figure 1. PRISMA (Preferred Reporting Items for Systematic Reviews and Meta-Analyses) flow chart.
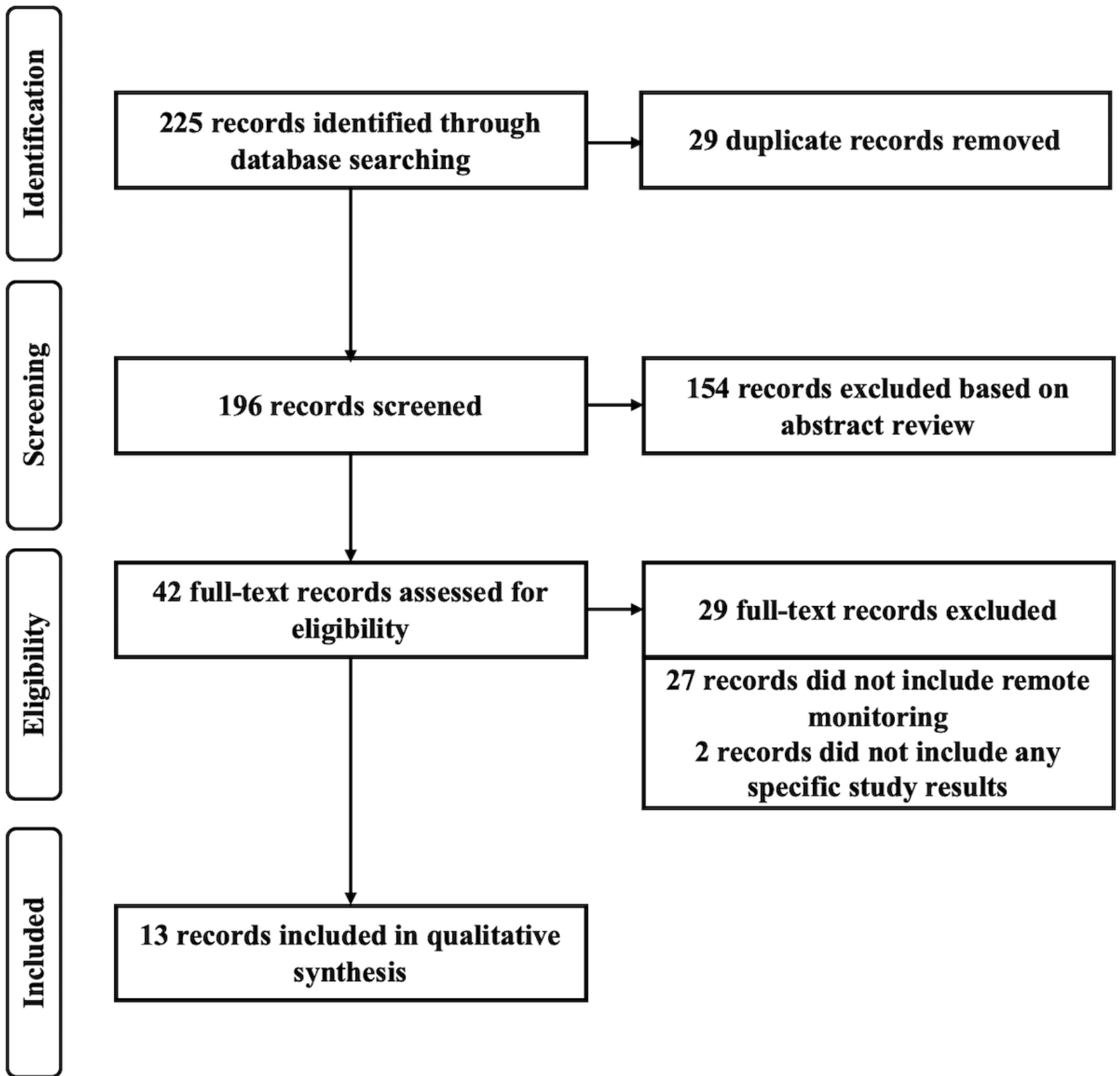

\section{Results}

The results of the literature review are summarized in Table 1. All 13 studies were published between 2014 and 2019. Four studies were randomized controlled trials that ranged from 83 to 1437 participants [12,26-28]. One study was a quasi-experiment (nonrandomized cohort study) with 144 participants [29]. Six studies were pilot trials that ranged from 6 to 33 participants [21,30-34]. There was 1 qualitative interview of 10 health care workers [35] and 1 user acceptance study with 11 participants [36]. The main goal of each of these studies was to evaluate the effectiveness of health coaching. Our review focused on the effectiveness of health coaching (human coach versus automated coaching system) combined with remote monitoring technology (RAM and RPM) for older adults. 
Table 1. Summary of results from the literature review.

\begin{tabular}{|c|c|c|c|c|c|c|c|}
\hline Study & Coaching intervention & $\begin{array}{l}\text { Type of remote } \\
\text { monitoring }\end{array}$ & Study type & $\begin{array}{l}\text { Sample } \\
\text { size, } \mathrm{n}\end{array}$ & Study duration & Condition monitored & Outcomes \\
\hline [12] & $\begin{array}{l}\text { Human coach and tele- } \\
\text { phone calls }\end{array}$ & $\mathrm{RPM}^{\mathrm{b}}$ & $\begin{array}{l}\text { Randomized } \\
\text { control trial }\end{array}$ & 1437 & 26 weeks & Chronic heart failure & $\begin{array}{l}\text { Re-admissions }\left(\mathrm{N}^{\mathrm{e}}\right) \text {, } \\
\text { mortality }(\mathrm{N}) \text {, and } \\
\text { quality of life }\left(\mathrm{Y}^{\mathrm{f}}\right)\end{array}$ \\
\hline [27] & $\begin{array}{l}\text { Human coach and tele- } \\
\text { phone calls }\end{array}$ & $\mathrm{RAM}^{\mathrm{c}}$ and RPM & $\begin{array}{l}\text { Randomized } \\
\text { control trial }\end{array}$ & 595 & 1 year & $\begin{array}{l}\text { Chronic heart failure, } \\
\text { diabetes }\end{array}$ & $\begin{array}{l}\text { Blood pressure }(\mathrm{N}) \text {, } \\
\text { body weight }(\mathrm{N}) \text {, } \\
\text { and quality of life } \\
(\mathrm{N})\end{array}$ \\
\hline [26] & $\begin{array}{l}\text { Human coach and tele- } \\
\text { phone calls }\end{array}$ & RAM & $\begin{array}{l}\text { Randomized } \\
\text { control trial }\end{array}$ & 83 & 12 weeks & Cancer & $\begin{array}{l}\text { Physical activity (Y) } \\
\text { and sedentary behav- } \\
\text { ior }(\mathrm{Y})\end{array}$ \\
\hline [28] & $\begin{array}{l}\text { Human coach, tele- } \\
\text { phone calls, and mobile } \\
\text { app }\end{array}$ & RAM and RPM & $\begin{array}{l}\text { Randomized } \\
\text { control trial }\end{array}$ & 131 & 26 weeks & Diabetes & $\begin{array}{l}\mathrm{HbA}_{1 \mathrm{c}}{ }^{\mathrm{h}} \text { level }(\mathrm{N}) \text {, } \\
\text { body weight }(\mathrm{Y}), \\
\text { and quality of life } \\
(\mathrm{N})\end{array}$ \\
\hline [29] & $\begin{array}{l}\text { Human coach, tele- } \\
\text { phone calls, SMS text } \\
\text { messages, online train- } \\
\text { ing, and social network- } \\
\text { ing }\end{array}$ & RAM and RPM & $\begin{array}{l}\text { Quasi-experi- } \\
\text { ment }\end{array}$ & 144 & 1 year & Diabetes & $\begin{array}{l}\operatorname{HbA}_{1 \mathrm{c}}(\mathrm{Y}) \text { and body } \\
\text { weight (Y) }\end{array}$ \\
\hline$[30]$ & $\begin{array}{l}\text { Human coach, DSS }{ }^{\mathrm{a}} \text {, } \\
\text { telephone calls, and ex- } \\
\text { ercise videos }\end{array}$ & RAM and RPM & Pilot study & 12 & 8 weeks & $\begin{array}{l}\text { Chronic obstructive } \\
\text { pulmonary disease }\end{array}$ & $\begin{array}{l}\text { Program adherence } \\
(\mathrm{Y}) \text { and patient satis- } \\
\text { faction }(\mathrm{Y})\end{array}$ \\
\hline [31] & $\begin{array}{l}\text { Human coach, tele- } \\
\text { phone calls, and SMS } \\
\text { text messages }\end{array}$ & RAM & Pilot study & 24 & 4 weeks & Cancer & $\begin{array}{l}\text { Physical activity (Y) } \\
\text { and fatigue (Y) }\end{array}$ \\
\hline [21] & $\begin{array}{l}\text { Human coach, DSS, } \\
\text { exercise videos, SMS } \\
\text { text messages }\end{array}$ & RAM and RPM & Pilot study & 33 & Various & General health & Behavior change $\left(\mathrm{I}^{\mathrm{g}}\right)$ \\
\hline$[33]$ & $\begin{array}{l}\text { Human coach, tele- } \\
\text { phone calls, and mobile } \\
\text { app }\end{array}$ & RAM and RPM & Pilot study & 21 & 26 weeks & Diabetes & $\begin{array}{l}\operatorname{HbA}_{1 \mathrm{c}} \text { level }(\mathrm{Y}) \text { and } \\
\text { body weight }(\mathrm{Y})\end{array}$ \\
\hline$[34]$ & $\begin{array}{l}\text { Automated coach, DSS, } \\
\text { SMS text messages, and } \\
\text { mobile app }\end{array}$ & RAM & Pilot study & 27 & 26 weeks & Diabetes & $\begin{array}{l}\mathrm{HbA}_{1 \mathrm{c}} \text { level }(\mathrm{Y}) \text { and } \\
\text { activity level (Y) }\end{array}$ \\
\hline$[35]$ & $\begin{array}{l}\text { Human coach and SMS } \\
\text { text messages }\end{array}$ & RAM & $\begin{array}{l}\text { Qualitative inter- } \\
\text { view }\end{array}$ & 10 & $N / A^{d}$ & General health & Inconclusive \\
\hline$[36]$ & $\begin{array}{l}\text { Human coach, tele- } \\
\text { phone calls, and mobile } \\
\text { app }\end{array}$ & RAM and RPM & $\begin{array}{l}\text { User acceptance } \\
\text { study }\end{array}$ & 11 & 26 weeks & Diabetes & User acceptance (Y) \\
\hline
\end{tabular}

aDS: decision support system.

${ }^{b}$ RPM: remote patient monitoring.

${ }^{\mathrm{c}} \mathrm{RAM}$ : remote activity monitoring

${ }^{\mathrm{d}} \mathrm{N} / \mathrm{A}$ : not applicable.

${ }^{\mathrm{e}} \mathrm{N}$ : not effective.

${ }^{\mathrm{f}} \mathrm{Y}$ : effective.

$\mathrm{g}_{\mathrm{I} \text { : inconclusive. }}$

${ }^{\mathrm{h}} \mathrm{HbA}_{1 \mathrm{c}}$ : hemoglobin $\mathrm{A}_{1 \mathrm{c}}$.

The predominate type of health coaching was via a human coach (12/13 studies) [12,21,26-33,35,36], whereas an automated health coaching system was employed in only 1 study [34].
Human coaching included an initial training session [12,24-26,28,31,36], periodic training sessions [29], scheduled periodic contact with patients [12,24-27,29-31,33,35,36], or 
interventional contact based on remote monitoring results $[12,21,28,32]$. Four studies employed the use of a DSS to augment or assist the health coach [21,30,32,34]. The DSSs included software programs that generated trends and alerts for the health coach based on the remotely monitored data [30], artificial intelligence systems that evaluated the remotely monitored data and provided recommendations to the health coach [21,32], and a fully automated system that monitored physical activity and provided tailored feedback to the patient based on the monitored results [34]. Four studies employed the use of a mobile app for remote monitoring [28,33,34,36]. RAM was the most common type of telehealth technology employed (12 studies) [21,26-36] followed by RPM (8 studies) $[12,21,27-30,33,36]$. Communication with the patient was via telephone only (7 studies) [12,26-28,30,33,36], SMS text messages only (4 studies) [21,32,34,35], or telephone and SMS text messages ( 2 studies) [29,31]. Study durations ranged from 2 weeks to 1 year with 6 studies lasting 26 weeks or longer. The conditions monitored included diabetes (6 studies) [27-29,33,34,36] cancer (2 studies) [26,31], chronic heart failure (2 studies) [12,27], chronic obstructive pulmonary disease (1 study) [30], and overall general health (3 studies) [21,32,35].

Effectiveness outcomes assessed included hospital admissions/re-admissions, mortality, hemoglobin $\mathrm{A}_{1 \mathrm{c}}\left(\mathrm{HbA}_{1 \mathrm{c}}\right)$ level, body weight, blood pressure, physical activity level, fatigue, quality of life, and user acceptance of the coaching program and technology. Of the 13 studies reviewed, 10 found coaching supported by telehealth technology to be effective in at least one of the outcomes assessed in the studies $[12,26,28-34,36]$. As much as 5 of the 6 studies that monitored diabetes found health coaching plus remote monitoring to be effective particularly for physical activity level and body weight $[28,29,33,34,36]$. Neither of the 2 studies that monitored chronic heart failure found health coaching plus remote monitoring to be effective $[12,27]$ except for improving one's quality of life in one of the studies [12]. Both studies that monitored patients with cancer found health coaching plus remote monitoring to be effective at improving the patient's physical activity level [26,31]. Only 1 [32] of the 3 studies that monitored general health $[21,32,35]$ found health coaching plus remote monitoring to be effective. In summary, the results indicate that health coaching plus remote monitoring can be effective at improving a patient's physical activity level, $\mathrm{HbA}_{1 \mathrm{c}}$ values, and in reducing body weight.

\section{Discussion}

\section{Principal Findings}

Health coaching that incorporates telehealth technologies has been implemented in older populations with mixed results. As much as 10 of the 13 studies reviewed found this method of health coaching to provide effective outcomes [12,26,28-34,36]. This literature review identified several gaps that warrant discussion or additional research.

\section{Human Versus Automated Coach}

One of the more prominent findings identified in this review was the dependence on a human to provide health coaching and interaction with the patient. As much as 12 of the 13 studies reviewed included a human coach [12,21,26-33,35,36], and thus the outcomes were probably heavily reliant on a human in the process. Four of the studies did include health coaching systems that incorporated the use of a DSS [21,30,32,34]; however, only 1 study completely replaced the human coach with a DSS [34].

The health coaching system in the Yom-Tov et al's pilot study [34] was fully automated in that neither the patient nor the health coach had to manually enter data or actions into the DSS or remote monitoring system after the patient's activity goals were established. A smartphone app recorded the patient's physical activity and transmitted the data to the DSS. A tailored daily feedback SMS text message was sent to each participant to encourage exercise. An algorithm determined the message to be sent based on whether the patient reached his/her activity goal the previous day. The study found that customizing or changing the daily message based on the actual physical activity performed was effective at getting the patient to increase daily activity whereas a constant daily reminder message was not effective. The use of a DSS to augment or replace human coaching indicates there is some movement toward augmenting the human coach with DSS technology. A benefit of using a DSS combined with remote monitoring is the ability to provide 24/7 continuous monitoring and intervention which may not be possible with a human coach. Although costs were not assessed in these studies, it is surmised that lessening the amount of direct human involvement in the coaching process should reduce overall cost. Additional studies should be performed with the focus of comparing the clinical and cost-effectiveness of the following 3 forms of health coaching: (1) human health coach only, (2) health coaching performed by a DSS only, and (3) a hybrid model of health coaching by a human coach augmented by a DSS.

\section{Telephone Versus Electronic Media Communications}

Another finding identified in this review was the heavy reliance on the use of a telephone to communicate with patients. Nine of the studies used a telephone for delivering coaching with mixed effectiveness results (2 of these studies augmented telephone communications with SMS text messages) [12,26-31,33,36]. The other 4 studies used DSS messages, SMS text messages, or video messages in lieu of telephone calls, also with mixed effectiveness results [21,32,34,35]. These results indicate that coaching effectiveness may not be dependent on the method of communication with the patient. Additional studies should be performed to evaluate the effectiveness and acceptance of using electronic media to communicate with the patient instead of live telephone calls.

\section{Use of Smartphone Apps}

Four studies included the use of a smartphone app as part of the integrated telehealth solution $[28,33,34,36]$ with positive results for 3 of these studies $[33,34,36]$. Only one of these studies specifically evaluated the acceptance of smartphone app technology by the patients [36]. A recent qualitative study interviewed 12 community-dwelling older adults (aged 65-78) and found that older adults were, in general, satisfied with using technology to help monitor and manage their health on a daily basis (albeit amid some fears that technology would replace 
human contact) [37]. Thus, there appears to be an opportunity to expand the use of technology, such as smartphone apps, as part of a telehealth system for older adults.

\section{Coachability of Patients}

Although not explicitly evaluated in the studies, it is probable that the results of these studies were dependent on the willingness of the patient to accept health coaching. Some of the studies evaluated the willingness of the patient to accept health coaching as part of the inclusion criteria while other studies only included patients who expressed an interest in the study. Thus, it can be assumed that most of the studies were biased toward those patients who are coachable. An opportunity exists to explore the effectiveness of health coaching using telehealth technology for patients who are not coachable.

\section{Limitations}

This literature review was focused on studies that included older adults (aged 65 and older) in the population assessed. Studies that excluded older adults were not included in our review, so the results should not be extrapolated to general populations. Most of the coaching interventions reviewed in this study included a human coach who provided feedback to participants via telephone calls. This type of coaching depends on the effort of the human coach to provide an adequate type of coaching to the participant which may or may not include all aspects of a robust coaching program (goal setting, education, encouragement, and feedback on health-related behaviors). In addition, the studies reviewed did not attempt to assess the capability of a human coach versus an automated health coaching system to effect behavior change. Additional research is needed to make this assessment. There was only 1 fully automated coaching intervention study found in our review, so no conclusion can be drawn regarding the effectiveness of automated health coaching interventions. Additional research is needed in the area of automated health coaching. The search criteria for this review focused first on health and wellness coaching that was then further filtered on remote monitoring as an element of the coaching. Several other studies of telehealth might have included coaching but not as a focus of the study.

\section{Conclusions}

Four inter-related issues face the health care industry: (1) the increasing numbers and percentage of older adults, (2) chronic disease management among this older population, (3) the desire of older adults to age in place, and (4) the cost of health care for older adults. Health coaching combined with telehealth technology has been shown to provide effective outcomes in 10 of 13 studies reviewed. Four studies included the use of a DSS to augment or replace the health coach with positive results. However, insufficient evidence of automated health coaching was found in our review to draw a conclusion regarding the efficacy of automated coaching. Although not assessed in these studies, the inclusion of automation in the health coaching process has the potential to reduce overall health care costs for older adults. The benefits of health coaching combined with telehealth are evident and should be further explored.

\section{Future Directions}

One of the more prominent findings identified in this review was the dependence on a human to provide health coaching and interaction with the patient. Thus, the outcomes were probably heavily reliant on a human in the process. Future studies need to assess the capability of automated coaching systems versus human coaches to affect health behavior changes. Another prominent finding was the use of live telephone calls to provide coaching to the patient. Future studies should be performed to evaluate the effectiveness and acceptance of using electronic media to communicate with the patient. The studies reviewed did not specifically evaluate coachability or the willingness of the patient to accept health coaching. An opportunity exists to explore the effectiveness of health coaching using telehealth technology for patients who are not coachable. This discrepancy should be investigated by including quality of life measures in future studies of coaching systems. As sensors for RPM and RAM become more advanced and affordable, much more data will be available to monitor and evaluate. With advances in big data analytics, DSSs will be better informed and able to identify interventions when necessary. Based on the results of this review, additional studies should be conducted of the expanded use of health coaching and DSSs as part of the health care solution for older adults. In addition, cost-effectiveness of health coaching combined with telehealth needs to be assessed against human-only health coaching methods. The results of these studies would inform the future direction of health coaching.

\section{Acknowledgments}

The lead author of this literature review (CM) is a qualified veteran who receives funding (tuition and fees) from the Texas Veterans Commission through the Hazlewood Act. There is no involvement by the Texas Veterans Commission in the review and approval of this study.

\section{Conflicts of Interest}

None declared.

\section{References}

1. About Chronic Disease. Atlanta, GA: Centers for Disease Control and Prevention; 2018. URL: https://www.cdc.gov/ chronicdisease/about/index.htm [accessed 2018-09-21]

2. Kochanek KD, Murphy SL, Xu J, Arias E. Deaths: Final Data for 2017. Natl Vital Stat Rep 2019 Jun;68(9):1-77 [FREE Full text] [Medline: $\underline{\text { 32501199] }}$ 
3. Centers for Disease Control and Prevention. The state of aging and health in America 2013. Atlanta, GA: Centers for Disease Control and Prevention/U.S. Department of Health and Human Services; 2013. URL: https://www.cdc.gov/aging/ pdf/state-aging-health-in-america-2013.pdf [accessed 2020-01-11]

4. De Nardi M, French E, Jones JB, McCauley J. Medical spending of the U.S. elderly (Report No.: 21270). Cambridge, MA: National Bureau of Economic Research; 2015 Jun. URL: https://www.nber.org/system/files/working papers/w21270/ w21270.pdf [accessed 2020-01-11]

5. How do health expenditures vary across the population? Peterson-KFF Health Syst Tracker. URL: https://www. healthsystemtracker.org/chart-collection/health-expenditures-vary-across-population/ [accessed 2020-05-31]

6. Colby SL, Ortman JM. Projections of the size and composition of the US population: 2014 to 2060. Suitland-Silver Hill, MD: U.S. Census Bureau; 2017. URL: http://wedocs.unep.org/bitstream/handle/20.500.11822/20152/colby_population.pdf [accessed 2021-01-11]

7. Khalfani-Cox L. What are the costs of aging in place?. 2017 Feb. URL: https://www.aarp.org/money/budgeting-saving/ info-2017/costs-of-aging-in-place.html [accessed 2021-01-11]

8. Satariano WA, Scharlach AE, Lindeman D. Aging, place, and technology: toward improving access and wellness in older populations. J Aging Health 2014 Dec;26(8):1373-1389 [FREE Full text] [doi: 10.1177/0898264314543470] [Medline: 25502245]

9. Nathan V, Paul S, Prioleau T, Niu L, Mortazavi BJ, Cambone SA, et al. A Survey on Smart Homes for Aging in Place: Toward Solutions to the Specific Needs of the Elderly. IEEE Signal Process. Mag 2018 Sep;35(5):111-119. [doi: $10.1109 / \mathrm{msp} .2018 .2846286]$

10. Wijesooriya NR, Mishra V, Brand PLP, Rubin BK. COVID-19 and telehealth, education, and research adaptations. Paediatr Respir Rev 2020 Sep;35:38-42 [FREE Full text] [doi: 10.1016/j.prrv.2020.06.009] [Medline: $\underline{32653468]}$

11. Chaudhry SI, Mattera JA, Curtis JP, Spertus JA, Herrin J, Lin Z, et al. Telemonitoring in patients with heart failure. N Engl J Med 2010 Dec 9;363(24):2301-2309 [FREE Full text] [doi: 10.1056/NEJMoa1010029] [Medline: 21080835]

12. Ong MK, Romano PS, Edgington S, Aronow HU, Auerbach AD, Black JT, Better Effectiveness After Transition-Heart Failure (BEAT-HF) Research Group. Effectiveness of Remote Patient Monitoring After Discharge of Hospitalized Patients With Heart Failure: The Better Effectiveness After Transition -- Heart Failure (BEAT-HF) Randomized Clinical Trial. JAMA Intern Med 2016 Mar;176(3):310-318 [FREE Full text] [doi: 10.1001/jamainternmed.2015.7712] [Medline: 26857383]

13. Kivelä K, Elo S, Kyngäs H, Kääriäinen M. The effects of health coaching on adult patients with chronic diseases: a systematic review. Patient Educ Couns 2014 Nov;97(2):147-157. [doi: 10.1016/j.pec.2014.07.026] [Medline: 25127667]

14. Oliveira JS, Sherrington C, Amorim AB, Dario AB, Tiedemann A. What is the effect of health coaching on physical activity participation in people aged 60 years and over? A systematic review of randomised controlled trials. Br J Sports Med 2017 Oct;51(19):1425-1432 [FRE Full text] [doi: 10.1136/bjsports-2016-096943] [Medline: 28320732]

15. Center for Connected Health Policy. About telehealth. 2019. URL: https://www.cchpca.org/about/about-telehealth [accessed 2020-01-02]

16. Hall A, Stellefson M, Bernhardt J. Healthy Aging 2.0: the potential of new media and technology. Prev Chronic Dis 2012;9:E67 [FREE Full text] [Medline: 22405474]

17. Weinstein RS, Lopez AM, Joseph BA, Erps KA, Holcomb M, Barker GP, et al. Telemedicine, telehealth, and mobile health applications that work: opportunities and barriers. Am J Med 2014 Mar;127(3):183-187. [doi: 10.1016/j.amjmed.2013.09.032] [Medline: 24384059]

18. Bratan T, Clarke M. Towards the design of a generic systems architecture for remote patient monitoring. Conf Proc IEEE Eng Med Biol Soc 2005;2006:106-109. [doi: 10.1109/IEMBS.2005.1616353] [Medline: 17282122]

19. Mahoney DF. An Evidence-Based Adoption of Technology Model for Remote Monitoring of Elders' Daily Activities. Ageing Int 2010 Sep 23;36(1):66-81 [FREE Full text] [doi: 10.1007/s12126-010-9073-0] [Medline: 21423843]

20. Welch G, Balder A, Zagarins S. Telehealth program for type 2 diabetes: usability, satisfaction, and clinical usefulness in an urban community health center. Telemed J E Health 2015 May;21(5):395-403. [doi: 10.1089/tmj.2014.0069] [Medline: 25748544]

21. Pavel M, Jimison HB, Korhonen I, Gordon CM, Saranummi N. Behavioral Informatics and Computational Modeling in Support of Proactive Health Management and Care. IEEE Trans Biomed Eng 2015 Dec;62(12):2763-2775 [FREE Full text] [doi: 10.1109/TBME.2015.2484286] [Medline: 26441408]

22. Jonk Y, Lawson K, O'Connor H, Riise KS, Eisenberg D, Dowd B, et al. How effective is health coaching in reducing health services expenditures? Med Care 2015 Feb;53(2):133-140 [FREE Full text] [doi: 10.1097/MLR.0000000000000287] [Medline: 25588134]

23. Moher D, Liberati A, Tetzlaff J, Altman DG. Preferred reporting items for systematic reviews and meta-analyses: the PRISMA statement. PLoS Med 2009 Jul 21;6(7):e1000097 [FREE Full text] [doi: 10.1371/journal.pmed.1000097] [Medline: 19621072]

24. Lynch BM, Nguyen NH, Moore MM, Reeves MM, Rosenberg DE, Boyle T, et al. Maintenance of physical activity and sedentary behavior change, and physical activity and sedentary behavior change after an abridged intervention: Secondary outcomes from the ACTIVATE Trial. Cancer 2019 Aug 15;125(16):2856-2860 [FREE Full text] [doi: 10.1002/cncr.32142] [Medline: $\underline{\text { 31012968] }}$ 
25. Lynch BM, Nguyen NH, Moore MM, Reeves MM, Rosenberg DE, Boyle T, et al. A randomized controlled trial of a wearable technology-based intervention for increasing moderate to vigorous physical activity and reducing sedentary behavior in breast cancer survivors: The ACTIVATE Trial. Cancer 2019 Aug 15;125(16):2846-2855. [doi: 10.1002/cncr.32143] [Medline: 31012970]

26. Lynch BM, Nguyen NH, Reeves MM, Moore MM, Rosenberg DE, Wheeler MJ, et al. Study design and methods for the ACTIVity And TEchnology (ACTIVATE) trial. Contemp Clin Trials 2018 Jan;64:112-117 [FREE Full text] [doi: 10.1016/j.cct.2017.10.015] [Medline: 29097298]

27. Karhula T, Vuorinen A, Rääpysjärvi K, Pakanen M, Itkonen P, Tepponen M, et al. Telemonitoring and Mobile Phone-Based Health Coaching Among Finnish Diabetic and Heart Disease Patients: Randomized Controlled Trial. J Med Internet Res 2015;17(6):e153 [FREE Full text] [doi: 10.2196/jmir.4059] [Medline: 26084979]

28. Wayne N, Perez DF, Kaplan DM, Ritvo P. Health Coaching Reduces HbA1c in Type 2 Diabetic Patients From a Lower-Socioeconomic Status Community: A Randomized Controlled Trial. J Med Internet Res 2015;17(10):e224 [FREE Full text] [doi: 10.2196/jmir.4871] [Medline: 26441467]

29. Sepah SC, Jiang L, Peters AL. Translating the Diabetes Prevention Program into an Online Social Network: Validation against CDC Standards. Diabetes Educ 2014 Apr 10;40(4):435-443. [doi: 10.1177/0145721714531339] [Medline: 24723130]

30. Benzo RP, Kramer KM, Hoult JP, Anderson PM, Begue IM, Seifert SJ. Development and Feasibility of a Home Pulmonary Rehabilitation Program With Health Coaching. Respir Care 2018 Feb;63(2):131-140 [FREE Full text] [doi:

10.4187/respcare.05690] [Medline: 29066590]

31. Gell NM, Grover KW, Humble M, Sexton M, Dittus K. Efficacy, feasibility, and acceptability of a novel technology-based intervention to support physical activity in cancer survivors. Support Care Cancer 2017 Apr;25(4):1291-1300. [doi: 10.1007/s00520-016-3523-5] [Medline: 27957621]

32. Jimison H, Hagler S, Kurillo G, Bajcsy R, Pavel M. Remote health coaching for interactive exercise with older adults in a home environment. Annu Int Conf IEEE Eng Med Biol Soc 2015;2015:5485-5488 [FREE Full text] [doi: 10.1109/EMBC.2015.7319633] [Medline: 26737533]

33. Wayne N, Ritvo P. Smartphone-enabled health coach intervention for people with diabetes from a modest socioeconomic strata community: single-arm longitudinal feasibility study. J Med Internet Res 2014;16(6):e149 [FREE Full text] [doi: 10.2196/jmir.3180] [Medline: 24907918]

34. Yom-Tov E, Feraru G, Kozdoba M, Mannor S, Tennenholtz M, Hochberg I. Encouraging Physical Activity in Patients With Diabetes: Intervention Using a Reinforcement Learning System. J Med Internet Res 2017 Oct 10;19(10):e338 [FREE Full text] [doi: 10.2196/jmir.7994] [Medline: 29017988]

35. Brandt CJ, Søgaard GI, Clemensen J, Søndergaard J, Nielsen JB. Determinants of Successful eHealth Coaching for Consumer Lifestyle Changes: Qualitative Interview Study Among Health Care Professionals. J Med Internet Res 2018 Jul 05;20(7):e237. [doi: 10.2196/jmir.9791] [Medline: 29980496]

36. Pludwinski S, Ahmad F, Wayne N, Ritvo P. Participant experiences in a smartphone-based health coaching intervention for type 2 diabetes: A qualitative inquiry. J Telemed Telecare 2015 Jul 21. [doi: 10.1177/1357633X15595178] [Medline: 26199275]

37. Cabrita M, Tabak M, Vollenbroek-Hutten MM. Older Adults' Attitudes Toward Ambulatory Technology to Support Monitoring and Coaching of Healthy Behaviors: Qualitative Study. JMIR Aging 2019 Mar 12;2(1):e10476 [FREE Full text] [doi: 10.2196/10476] [Medline: $\underline{31518252]}$

\section{Abbreviations}

ADL: activity of daily living

DSS: decision support system

PRISMA: Preferred Reporting Items for Systematic Reviews and Meta-Analyses

RAM: remote activity monitoring

RPM: remote patient monitoring

Edited by A Kushniruk; submitted 23.08.20; peer-reviewed by D Chrimes, $N$ Wayne, A Martínez-García, R Goodison, E Stringer; comments to author 18.10.20; revised version received 17.12.20; accepted 23.12.20; published 29.01.21

Please cite as:

Markert C, Sasangohar F, Mortazavi BJ, Fields $S$

The Use of Telehealth Technology to Support Health Coaching for Older Adults: Literature Review

JMIR Hum Factors 2021;8(1):e23796

URL: http://humanfactors.jmir.org/2021/1/e23796/

doi: $10.2196 / 23796$

PMID: 33512322 
(C) Carl Markert, Farzan Sasangohar, Bobak J Mortazavi, Sherecce Fields. Originally published in JMIR Human Factors (http://humanfactors.jmir.org), 29.01.2021. This is an open-access article distributed under the terms of the Creative Commons Attribution License (https://creativecommons.org/licenses/by/4.0/), which permits unrestricted use, distribution, and reproduction in any medium, provided the original work, first published in JMIR Human Factors, is properly cited. The complete bibliographic information, a link to the original publication on http://humanfactors.jmir.org, as well as this copyright and license information must be included. 